\title{
Correlations between some physico-chemical properties of sunflower oil
}

\author{
Anişoara-Arleziana NEAGU ${ }^{\mathrm{a}}$, Irina NIȚA ${ }^{* a}$ and Elisabeta BOTEZ \\ a Department of Chemistry and Chemical Engineering, ,Ovidius” University of Constanta, 124 Mamaia Blvd., \\ Constanta 900527, Romania \\ ${ }^{b}$ Department of Food Science, Food Engineering, Aplied Biotechnology, "Dunărea de Jos" University, 111 \\ Domneasca Street, Galați 800201, Romania
}

\begin{abstract}
The major objective of this study is to report physico-chemical properties of sunflower oil samples collected from different stages of the technological process for sunflower oil refining for food industry. The samples of oil were crude oil, washed oil, bleached oil and deodorized oil. The physico-chemical properties of sunflower oil experimentally determined were density, saponification value (SV), iodine value (IV), and acid value (AV). It was found that the density of sunflower oil remains approximately constant over the different stages of the manufacturing flow of cooking oil, except the crude oil. The acid value significantly decreases from crude oil (2.588) to deodorized oil (0.366). The iodine value and saponification value of the different samples of the sunflower oil corresponding to different stages of oil processing varies slightly. The capacity of different models to accurately correlate and/or predict the density of vegetable oil was tested. The density of sunflower oil can be accurately estimated from its SV and IV or with an empirical equation, when density data are available.
\end{abstract}

Keywords: density, sunflower oil, physico-chemical properties.

\section{Introduction}

Vegetable oil is produced in Romania since the first half of the eighteenth century [1]. Currently, sunflower (Helianthus annuus L) is a major oil seed crops, ranking fourth in world production [2]. Sunflower oil represents the main edible oil used in Romania. It represents an important source of fat in diet being used for frying, salad dressing, cooking and also for margarine production. Studies on the physico-chemical properties of sunflower oil are presented in literature [3-5].

The main steps of chemical refining of sunflower oil are degumming (gums removal of crude oil), neutralization and washing (removal of free fatty acids and washing soap), bleaching (removal of colored impurities), winterization (removal of waxes) and deodorizing (removal of volatile components that prints oil smell and unpleasant taste) [6].
The aim of this paper is to report physicochemical properties (density, saponification value, iodine value, and acid value) of commercial cooking sunflower oil and of samples of oil collected from different stages of the manufacturing flow of cooking oil. The capacity of different models to accurately correlate and/or predict the density of vegetable oil will be tested.

\section{Experimental}

\subsection{Samples and reagents}

Samples of sunflower oil corresponding to different stages of vegetable oil processing were supplied by a local company. The samples were represented by crude oil (CO), washed oil (WO), bleached oil (BO), and deodorized oil (DO). They were stored in the dark, in stoppered bottles.

Some characteristics of the deodorized sunflower oil used in the experiment are presented in Table 1. 
Table 1. Characteristics of the sunflower oil

\begin{tabular}{|l|l|}
\hline Property & Value \\
\hline Saturated fatty acids & $11 \mathrm{~g}$ \\
\hline Unsaturated fatty acids & $24 \mathrm{~g}$ \\
\hline Polyunsaturated & $57 \mathrm{~g}$ \\
\hline
\end{tabular}

"as presented by the producer, per $100 \mathrm{~g}$ oil sample.

The reagents used to determine the saponification value, iodine value and acid value were: potassium hydroxide, hydrochloric acid, potassium iodide, sodium thiosulfate and chloroform from Chemical Company Iasi, Romania, Hanus reagent and ethanol from S.C. Remed Prodimpex S.R.L. Bucharest, Romania. All reagents used in the study were of analytical grade. The solutions were prepared with by-distilled water.

\subsection{Equipment}

The density was measured with an Anton-Paar viscometer SVM 3000 type. The measurements were made in the temperature range of $20{ }^{\circ} \mathrm{C}$ to $80{ }^{\circ} \mathrm{C}$. The uncertainty in density measurements was \pm $0.0005 \mathrm{~g} / \mathrm{cm}^{3}$. The temperature in the measuring cell was controlled to within $\pm 0.02^{\circ} \mathrm{C}$. All measurements at each temperature were repeated three times, and the results were averaged.

The density was determined at atmospheric pressure according to the method ASTM D445 standard. The acid value (AV), iodine value (IV), and saponification value (SV) were determined following the procedures as presented elsewhere [7]. The saponification value, iodine value and acid value were determined according to SR EN ISO 3657:2005 (SV), SR EN ISO 391:2002 (IV) and SR EN ISO 660:2009 (AV).

\section{Empirical models}

Empirical predictive-correlative equations used to calculate the density of sunflower oil from physical-chemical properties like saponification value and iodine value are presented in literature: Pantzaris equations [8 - 9]:

$\rho=0.8534+0.000308 \cdot 5 V+0.000157 \cdot I V-0,00068 \cdot t$ $\rho=0.8475+0.050308 \cdot 5 V+0.000271 \cdot W-0.0068 \cdot t$

The decrease of vegetable oil density with temperature is of linear nature [10 - 11]:

$$
p=a t+b
$$

where $\rho$ represents the density of the oil; SV saponification value; IV - iodine value; $\mathrm{t}$ temperature $\left({ }^{\circ} \mathrm{C}\right) ; a$ and $b$ are constant parameters.

The accuracy of empirical equations used to estimate the density of vegetable oil at different temperatures was evaluated using the corresponding values of relative error (RE) calculated with the equation:

$R E=\frac{\rho_{\text {exp }}-\rho_{\text {calc }}}{\rho_{\text {exp }}}$

and the average absolute deviation (AAD) calculated with the equation:

$A A D=\frac{100}{n} \sum_{i=1}^{n} \frac{\sqrt{\left(\rho_{\mathrm{axp}_{i}}-\rho_{\mathrm{cal} c_{i}}\right)^{2}}}{\rho_{\mathrm{ar} p_{i}}}$

where $\rho_{\exp }$ and $\rho_{\text {calc }}$ are the measured and calculated value of the density, $n$ represents the number of experimental points.

\section{Results and Discussions}

The experimentally determined values of density, saponification value (SV), iodine value (IV), and acid value (AV) of the studied samples of sunflower oil are presented in Table 2 and 3.

Table 2. Experimental density $\left(\mathrm{g} / \mathrm{cm}^{3}\right)$ of crude, washed, bleached and deodorized sunflower oil

\begin{tabular}{|c|c|c|c|c|}
\hline $\begin{array}{c}\text { Temperature } \\
\left({ }^{\circ} \mathrm{C}\right)\end{array}$ & $\begin{array}{c}\text { Crude } \\
\text { oil } \\
(\mathrm{CO})\end{array}$ & $\begin{array}{c}\text { Washed } \\
\text { oil } \\
(\mathrm{WO})\end{array}$ & $\begin{array}{c}\text { Bleached } \\
\text { oil } \\
(\mathrm{BO})\end{array}$ & $\begin{array}{c}\text { Deodorized } \\
\text { oil } \\
(\mathrm{DO})\end{array}$ \\
\hline 20 & 0.9191 & 0.9185 & 0.9185 & 0.9184 \\
\hline 40 & 0.9055 & 0.9185 & 0.9049 & 0.9048 \\
\hline 60 & 0.8923 & 0.8914 & 0.8915 & 0.8914 \\
\hline 80 & 0.8788 & 0.8782 & 0.8782 & 0.8782 \\
\hline
\end{tabular}

It can be seen (Table 2) that the density of sunflower oil remains approximately constant over the different stages of the manufacturing flow of cooking oil, except the crude oil. The density decreases with temperature increasing. 
Table 3. Chemical properties of crude, washed, bleached and deodorized sunflower oil

\begin{tabular}{|c|c|c|c|c|}
\hline Property* & $\begin{array}{c}\text { Crude } \\
\text { oil } \\
\text { (CO) }\end{array}$ & $\begin{array}{c}\text { Washed } \\
\text { oil } \\
\text { (WO) }\end{array}$ & $\begin{array}{c}\text { Bleached } \\
\text { oil } \\
\text { (BO) }\end{array}$ & $\begin{array}{c}\text { Deodorized } \\
\text { oil } \\
\text { (DO) }\end{array}$ \\
\hline SV & 212.143 & 209.776 & 209.476 & 209.448 \\
\hline IV & 85.916 & 82.752 & 83.562 & 83.824 \\
\hline AV & 2.588 & 0.536 & 0.468 & 0.366 \\
\hline
\end{tabular}

*SV - saponification value; IV - iodine value; AV acid value.

The acid value (Table 3) significantly decreases from crude oil to deodorized oil, as a result of the treatment during washing, bleaching and refining steps of the manufacturing process. The iodine value and saponification value of the different samples of the sunflower oil corresponding to different stages of oil processing varies slightly from sample to sample.

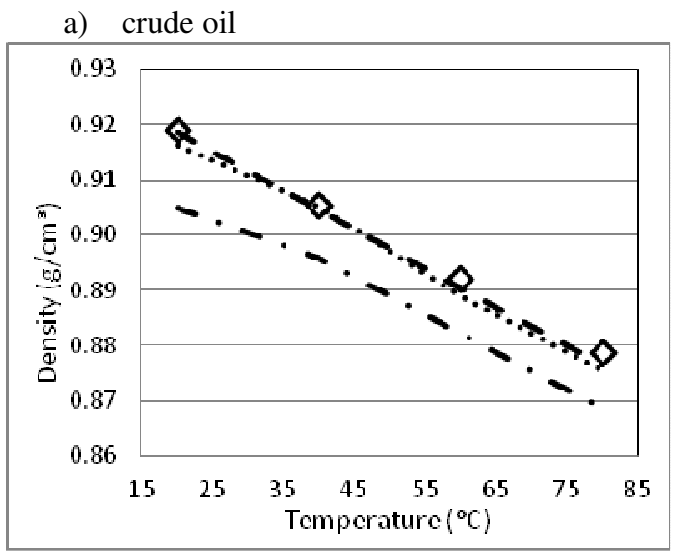

b) washed oil

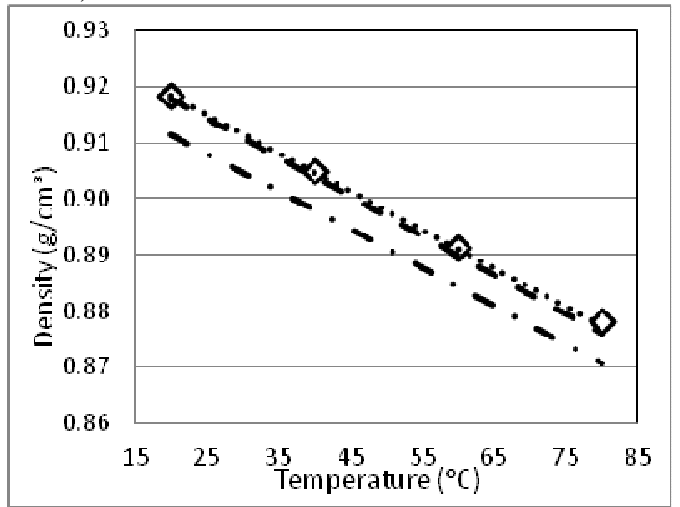

c) bleached oil

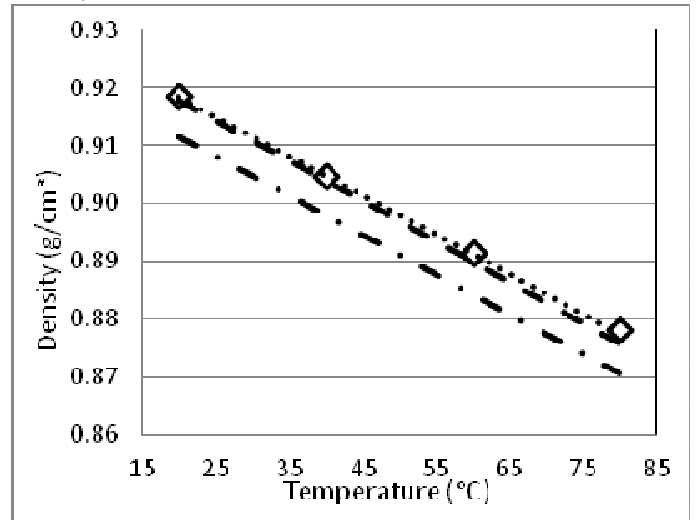

d) deodorized oil

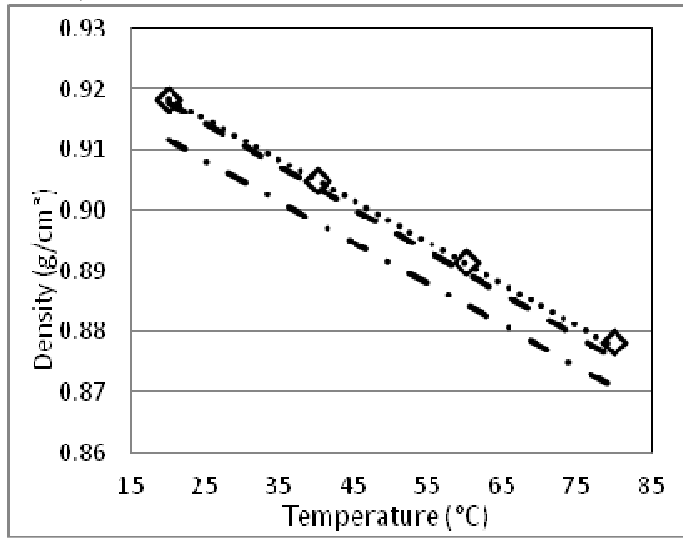

Fig. 1. Density of sunflower oil versus temperature; $\checkmark$ experimental value; (....) calculated with eq.(1); (- -) calculated with eq.(2); (-) calculated with eq.(3)

Experimental and calculated density (eqs.1, 2 and 3) versus temperature for sunflower oil samples are presented in Fig. 1 a, b, c, d. It can be observed that the estimation of the density using eqs. (1) and (3) has a good accuracy, while eq. (2) underestimates oil density. The accuracy of the selected equations for density estimation was evaluated by the means of RE and AAD statistical indicators.

The constants from eq.(3) for the calculation of the density of sunflower oil at different temperatures 
determined based on experimental density values, using a linear regression are presented in Table 4.

Table 4. Correlation parameters from eq.(3)

\begin{tabular}{|l|l|l|l|}
\hline \multirow{2}{*}{ Oil type } & \multicolumn{2}{|l|}{ Correlation parameters (eq.3) } & \multirow{2}{*}{$\mathrm{R}^{2}$} \\
\cline { 2 - 3 } & $\mathrm{a}\left(\mathrm{g} / \mathrm{cm}^{3}\right.$.grd $)$ & $\mathrm{b}\left(\mathrm{g} / \mathrm{cm}^{3}\right)$ & \\
\hline Crude oil & -0.0007 & 0.9325 & 0.9999 \\
\hline Washed oil & -0.0007 & 0.9319 & 0.9999 \\
\hline Bleached oil & -0.0007 & 0.9319 & 0.9999 \\
\hline $\begin{array}{l}\text { Deodorized } \\
\text { oil }\end{array}$ & -0.0007 & 0.9317 & 0.9999 \\
\hline
\end{tabular}

The RE varied between 0.0006 and 0.003 when the density of sunflower oil is calculated with eqs. (1) or (3), and varied between 0.007 and 0.01 when eq. (2) is applied. AAD is no more than $0.3 \%$ when the density is calculated with eqs. (1) or (3), and is an order of magnitude higher for eq. (2).

\section{Conclusions}

Density, saponification value, iodine value and acid value were determined for four samples of sunflower oil corresponding to different stages of vegetable oil processing. It was found that the density of sunflower oil remains approximately constant over the different stages of the manufacturing flow of cooking oil, except the crude oil. The acid value significantly decreases from crude oil (2.588) to deodorized oil (0.366). The iodine value and saponification value of the different samples of the sunflower oil corresponding to different stages of oil processing varies slightly.

The density of sunflower oil can be estimated with correlative-predictive equations based on SV and IV values of the oil, or with a predictive equation, when density data are available. Equations (1) and (3) can be recommended for sunflower oil density calculation with a good accuracy.

\section{References}

* $\quad$ E-mail address: inita@ univ-ovidius.ro

[1]. C. Banu, Handbook of food industry engineer (in Romanian), Editura Tehnica, Bucuresti, 2002.

[2]. www.dce.gov.ro

[3]. N. A. Fakhri and H. K. Qadir, Journal of Environmental Science and Engineering, 5, 844 (2011).

[4]. M. A., Aboki, M. Mohammed, S. H. Zuru, H. M. Aliyu, M. Gero, I. M. Alibe and B. Inuwa, International Journal of Science and Technology, 2 (4), 151 (2012).

[5]. M. K. Sabah EL-Kheir, A. A. Alamin, H. N. Sulafa and A. K. Sabi Ali, ARPN Journal of Science and Technology, 2 (3), 177 (2012).

[6]. R. D. O'Brien, Fats and Oils: formulating and processing for applications - 2nd ed., CRC Press LLC, 2004.

[7]. A.A., Neagu, I., Nita, E. Botez and S. Geacai, Ovidius University Annals of Chemistry, 24 (2), 11 (2013).

[8]. F. Gunstone, Oils and Fats in the Food Industry, Blackwell Publshing Ltd., 2008.

[9]. F. Gunstone, Rapeseed and Canola Oil: Production, Processing, Propeties and Uses, Blackwell Publishing Ltd., 2004.

[10]. B. Esteban, J-R. Riba, G. Baquero, A. Rius, and R. Puig, Biomass and Bioenergy, 42, 164 (2012).

[12]. C. M. Rodenbush, F. H. Hsieh and D. S. Viswanath, J Am Oil Chem Soc, 76, 1415 (1999).

Submitted: November $3^{\text {rd }} 2014$ Accepted in revised form: November $16^{\text {th }} 2014$ 